\title{
Assessment of a sustainable rural development model: best practices in Comala, Colima, Mexico
}

\author{
R. Zizumbo-Villarreal ${ }^{1}$ \& R. I. Roja-Caldelas ${ }^{2}$ \\ ${ }^{I}$ Facultad de Ciencias, Universidad de Colima, México \\ ${ }^{2}$ Facultad de Arquitectura y Diseño, \\ Universidad Autónoma de Baja California, México
}

\begin{abstract}
The approach to sustainable rural development in Mexico has been implemented since 2000 with the creation of the Rural Development Law (RDL). This proposal has been applied over almost ten years in different levels of management projects; national, state, regional and municipal, which have followed two types of planning processes: the first, a macroeconomic perspective that articulates projects with regional impact (top-down); and the second, a planning development view promoted from local communities (bottom-up) in order to have a direct impact over marginalized population, in both cases integrating environmental and ecological assessment of natural resources. The $\mathrm{RDL}$ also calls for coordination and convergence of different sector interests to achieve multiple objectives of projects. Such approach takes into account social, economic, environmental, technological and political-institutional aspects to assess development proposals. From this perspective, the present study aims to set the framework of Sustainable Rural Development in Mexico and to assess the achievements and shortcomings of the RDL model based on available information from best practices reported to the National Network of Sustainable Rural Development database 2006-2009 for the State of Colima, Mexico. Finally, results are demonstrating little achievements related to the integration of social organizations, better management practices and technical training levels. Keywords: sustainable development, territorial approach, rural development, resource management.
\end{abstract}




\section{Introduction}

The rural development framework (RD) has kept on modifying as the conditions in rural areas have become more complex and diverse. Such is the case of the Green Revolution, which emerged as an economical modernizer thought, trying to incorporate rural population to the national development from the 1950 s to the $70 \mathrm{~s}$, based on the scientific and technological progress of the agricultural production and the change on the industrialization and urbanization processes that the country faced on those decades. Even though this movement had positive impacts on the increase production, it was not enough to cease poverty on rural population due to the lack of land, employment and funding, coupled with environmental impacts of the excessive use of agrochemicals and the social impacts regarding the attempt of improving the population's wellbeing conditions [1].

In the 1960s, the Integrated Rural Development concept emerged, whose purpose was to have a balance between the variables involved in the RD processes. This model was proposed from different disciplinarian viewpoints involved with the agrarian and based on a wide social and governmental involvement, framed within a national and international context. Just as the Green Revolution, it also emphasizes on the eradication of poverty, facing the need to satisfy the population's basic needs through the increase of productivity and the distribution of the means of production [ibid]. Although it was an interdisciplinary approach, it focuses only on the agricultural side and not in a wide perspective of rural economy, where the territory and other productive and human settlement activities act together, in addition of having multidisciplinary formulation elements and elements of integral analysis of variables such as social, agronomical, environmental, political and of institutional character, which places it in the agricultural sectorial management of rural areas.

The Sustainable Development (SD) concept arises from the international meetings regarding the environment and development (1972 and 1992), which arouse the interest and the need to incorporate ecological and environmental issues to the development of productive activities in both urban and rural life. As a result of this movement comes the SD proposal paradigm that will also be applied to the urban, rural, and natural resources management development. This proposal considers three main lines of action: the economical, the environmental and the social, that under a holistic vision can address complex problems seamlessly. This perspective joins the concept of RD during the 1990s in developed countries, and from there, adapts to the Latin-American context, to be called Sustainable Rural Development (SRD). The singularity of this proposal is the integration of territory as the main part in which a series of historicalcultural, economical, social, political-institutional and environmental processes are developed, and that it is subsequently called Sustainable Rural Development with a Territorial Approach (SRDTA).

The SRDTA's strategy takes its roots from the LEADER program (Liaisons entre Activités de Developement de l'Economie Rural). The program's proposal takes into account in its planning framework the diversity of the territories 
integrating the European Union; and as such promotes the community's involvement on the planning and management processes, which also implied the strengthening of the institutional linkage of the local areas and the productive transformation. The LEADER program has been integrated and adjusted to the Latin-American context, there is the work done by Schejtman and Berdegué [2] and by Sepúlveda et al. [3], Boisier [4] and Carton de Grammont [5].

Within the Latin-American frame, Miranda and Matos [6] clearly state the way they incorporate sustainability to the model through their different dimensions, which coupled with the territory's attributes are going to give form to the SRD concept with a territorial approach, that in Mexico's case is made explicit in the projects, plans and programs evaluation criteria. The dimensions are as following; a) Environmental: part in which every place counts with a determined ecosystem, with different types of renewable and non-renewable resources and that its sustainability in time will depend on their quality and its renewable capacity, in addition to the soil's conservation, relief and weather; b) Economical: contemplates the general economical dynamic and considers the economical-commercial relations in the territory's context; the productive structures; the relative weight of the productive sectors, the productive chains and the relevant economical complexes; the conditions and the infrastructure's offer (transport, energy and communication); the economical logistic, the competitive advantages and the potentialities or opportunities that the market offers; c) Technological: studies the dominant technological pattern in the territory and the level of general productivity differentiated by economical sectors or segments. It describes, qualitatively, the critical points, shortcomings and demands that affect the productivity and compromise the quality of the products, aiming for a production raise associated to the environmental sustainability (ecosystem adequacy). Also forming part are the rural extension, the innovation and scientific and technological training linked to the academy and the rating of the existing human resources; d) Social: considers the population's socio-demographic characteristics; the growth's structure and trends, social relations, employment, rent's structure, the citizenship, the offer and quality if the social infrastructure and public services, work relations; e) Cultural: it includes an anthropological analysis of the social groups that form each territory, including their different historical-cultural, artistic, and craft manifestations. It seeks to understand, among others, the common cultural identity and its different manifestation forms (culinary, production and marketing), religious, ethical and moral values, customary rules, the various forms of relation both internally and externally to the territory, the existing solidarity and cooperation networks; f) Political-institutional: it is linked with the practice of the local power and the external relations established with distinct levels of power; it includes the political system analysis and the prevailing power structure, of the social actors and their interests, of the State organizations and society.

While discussing the integration of the "Rural Territory" concept, both authors refer it to those spaces in which one or more human settlements linked with one another are to be found, where productive units of distinct sizes, 
division of labor and production and consumption chains are observed. The RT can be bounded by a micro-basin, bioregion, micro-region or to a group of municipalities that, nonetheless, put at the disposal of the observer a unique natural and cultural identity. Therefore, the environmental and the geographical space consolidation will depend on achieving its social and territorial cohesion, where social cohesion is understood as the expression of the rural community and the national societies integrated by equity principles, solidarity, social justice and territory belongingness. It emerges as a challenge to achieve the rural economy's inclusion and integration, both in its internal dynamics as in its relation with the national and global economy. Territorial cohesion is understood as the integration of spaces, resources, economies, societies and institutions, intertwining and modeling regions; territoriality that eases the definition of RD public politics, environmental management and human settlements. As particularities of the TA, the following points are considered: 1) Part of the territory's heterogeneity; 2) Recognizes that in the RT an urban dimension which needs to be synergistically integrated exists; 3) Admits that "the rural" is no longer synonymous with "the agricultural", as its productive activities diversify and its socioeconomic structure modifies; 4) Considers the diversity of functions (economical, social, cultural) that a natural system has, the multiple use of resources and its impact on social and economic systems; 5) Indicates the territory as a social construction of itself over the time as from its history, culture and institutions that give it its specificity and that manifest in different appropriation forms of NR, products and landscapes of each location; 6) Sustainable management of the environment and NR as central element of the poverty reduction strategies; 7) Institutional change in the land management, move from a sectorial to an integrated, concurrent and coordinated management; 8) Establishes institutional mechanisms that generate options for a participatory system that allows a consistent planning commensurate with societal demands.

Under this reference framework, the adaption to the Mexican context of the European and Latin-American paradigm is realized, achieved with the publication of the Sustainable Rural Development Law (SRDL) to begin in 2001 [8]. The changes show a great progress compared with the previous RD concepts and in the institutional operation integrated in a sectorial manner, which still shows signs of delay in its implementation through a coordination, concurrence and sectorial entailment, making it difficult to assess despite having almost 10 years of operation, well exemplified by the RENDRUS projects case.

\section{Sustainable rural development in Mexico}

The SRDL lays the foundations for the national RD as state policy, where the reference points for a comprehensive vision of the SRDTA that allows the active participation of rural society with concurrence and sectorial coordination, as well as with the authorities of the three government levels and according to the environment in which it develops in a decentralized manner, are considered fundamental [7]. 
The project is structured over four lines of action that provide the basis of the territory use as a unit of multidimensional and multi-sectorial management that integrates different types of capital: social, human, economic and natural, thus aiming to achieve greater social commitment, equity, plurality and democratic participation, figure 1 .
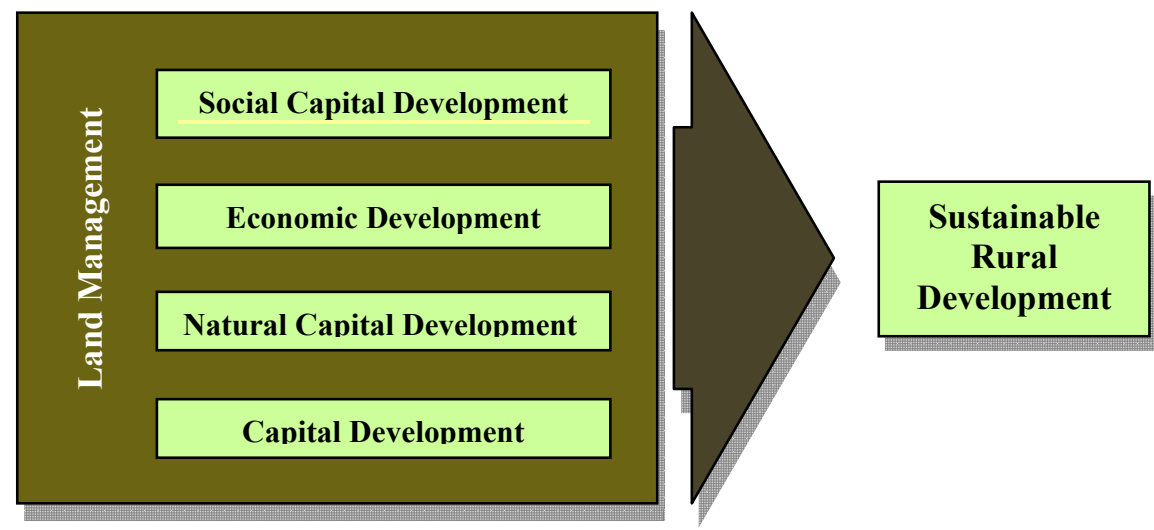

Figure 1: $\quad$ Sustainable rural development lines of action.

The $\mathrm{RD}$ is then presented as an alternative to improve the living standards through the development of productive activities, generation of reliable and appropriate information, a scientific, technical and technological development through the application of technology transfer packages designed according to the territorial and cultural needs with better public services, health, housing, culture, education, recreation in a democratic environment where social involvement is based on family.

This alternative focuses on the capacity building of the rural sector population with a two-way impact: the first, to influence in assistance programs to attack poverty with un-repayable resources; and the second, on business development programs oriented to the generation of employment and self-employment sources. Regarding the companies, the diversified production in primary activities is promoted: agriculture, livestock, forests, extractive, fishing and aquaculture, as well as agribusiness, industry, crafts, environmental services and tourist and recreational services. With this, the broadening of the RD concept towards the non-agricultural activities is intended. This vision pretends to achieve in a short term the mentality change and the rural population's interest to achieve an equitable distribution of the value network's income and a better performance in the sectorial relations that promotes poverty eradication [ibid].

The territory under this Mexican version is limited to the political and institutional management structure based on a national, state, district and municipal system, operating the RD planning in two directions: bottom-up through the planning of community projects supported through the municipal 
management derived from a territorial municipal diagnostic and articulated with the SRD municipal plans, where it is possible that some of them incorporate the district planning based in the system-product that tries to see the productive linkages around a product produced in different territories, such as the case of coffee, coconut and lemon in the state of Colima, Mexico; or as the shared management of a resource such as water or forests through micro-basins or bioregions, exemplified in the structure of Figure 2.

Councils

Management Level

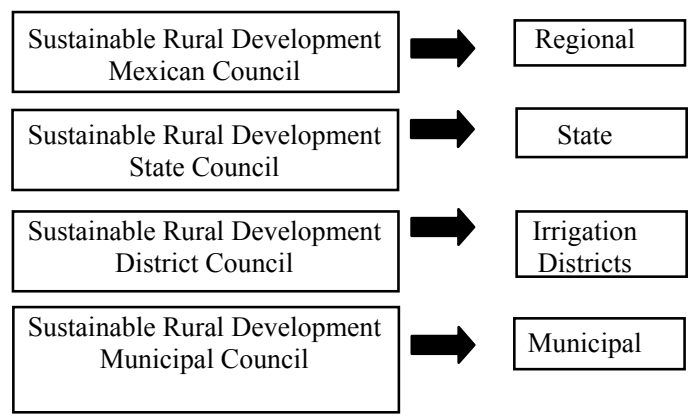

Public and Private

Participation

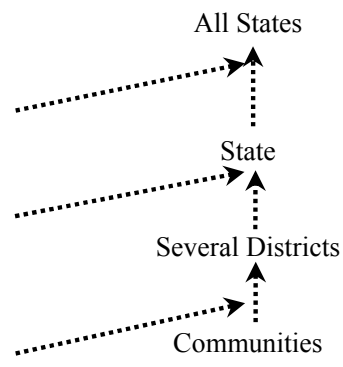

Figure 2: $\quad$ Territorial management structure of the SRD in Mexico.

Economic supports to improve the settlement's living standards are also contemplated in the model: infrastructure, housing, urban equipment, municipal public services and the regional infrastructure required for the production through Concurrent Special Programs between the sectorial institutions and the three government levels [8]. The territory, like in the general model, develops according to its social and spatial cohesion based on its own characteristics with their base on the culture, which is the result of the environment's and society's interaction through the different institutions that make it easier to establish different types of interactions with other territories.

In Figure 2, different planning scales are presented, where the communal corresponds to the system's first step in gradually integrating with other levels. The case of the Sustainable Rural Development National Network (RENDRUS) projects exemplifies it; some have become part of District Projects (Irrigation Districts) totaling several producers located in different municipalities, such as the case of coffee producers in Colima.

\section{Methodology}

The work is based on the review of 55 successful RENDRUS cases for the 20062009 period presented in the state of Colima. For this, an annual database was built, where the information of the annual RENDRUS events was captured. It is relevant to mention that, even though all participants are asked to fulfill the content requirements, at the moment of integrating the material in PowerPoint 
presentations or in text versions, not all present complete data. The information provided by the enterprises companies is based on a mainly qualitative evaluation of their achievements for the year they are competing, although there are also cases where quantitative information is presented.

The projects participate in three categories: first, primary production; second, transformation and marketing of the primary production/primary production transformation and marketing; and third, services and nonagricultural industry. The participants must belong to the "Desarrollo Rural de Alianza Contigo" program and their projects must meet the following points: name, location, background, objectives, production process, the group's organization chart and received training, marketing, impacts, future perspectives, success and adverse factors.

The evaluation of projects considered best practices is based on six criteria, which coincide with the RENDRUS reference framework concepts. It is worth mentioning that, at the time of the study, the responsible institutions did not count with indicators to facilitate the objective evaluation and the proposals' systematic monitoring. However, the contribution of the enterprises' selfassessment provides a feedback for multiple management of projects. The base criteria are: I. Technological and Productive Innovation: The Technology used in this project is allowing the production costs reduction and providing a better quality product. Considers it an innovative technology suitable to the area conditions; II. Organization and Administration: Participation and involvement from project members exist. They regularly meet to define their strategies. They keep production and accounting records; III. Quality, Surplus Value and Market Development: the project's offered products and services generate surplus value, have quality control and capture an increasing number of satisfied customers/clients; IV. Technical Training and Assistance: project members have constant training, thus allowing the company's consolidation; V. Social and Economic Impact: the project is generating jobs in the community and/or is improving the participants income level and living standards; VI. Sustainability and Environment: the project does not impair or improve the location's site environmental conditions.

\section{Successful experiences: SRDNN projects}

The employment and wealth generation in the rural sector is the result of the rural enterprises' successful operation. The empirical evidence shows that this companies' success is mainly explained by its own management, namely for the efficient management of its resources, rather than for its endowment assets. This means that the key to success for enterprises is counting with the knowledge, capabilities, processes, organizational networks and principles that allow the best use of its resources RENDRUS-SAGARPA [9].

Such is the case of the rural family production units, which are predominant in the sector and that base their competitiveness in the family members' work capacity and great flexibility, which makes them ideal for participating advantageously in agricultural activities not subject to traditional working hours. 
RENDRUS was founded in 1996 in order to strengthen the identification, systematization and exchange of successful business experiences that rural dwellers develop around the country. It is about an instrument for rural entrepreneurs that allow them to learn from other entrepreneurs' hits and misses and especially to reflect on their own experience and to identify improvement processes.

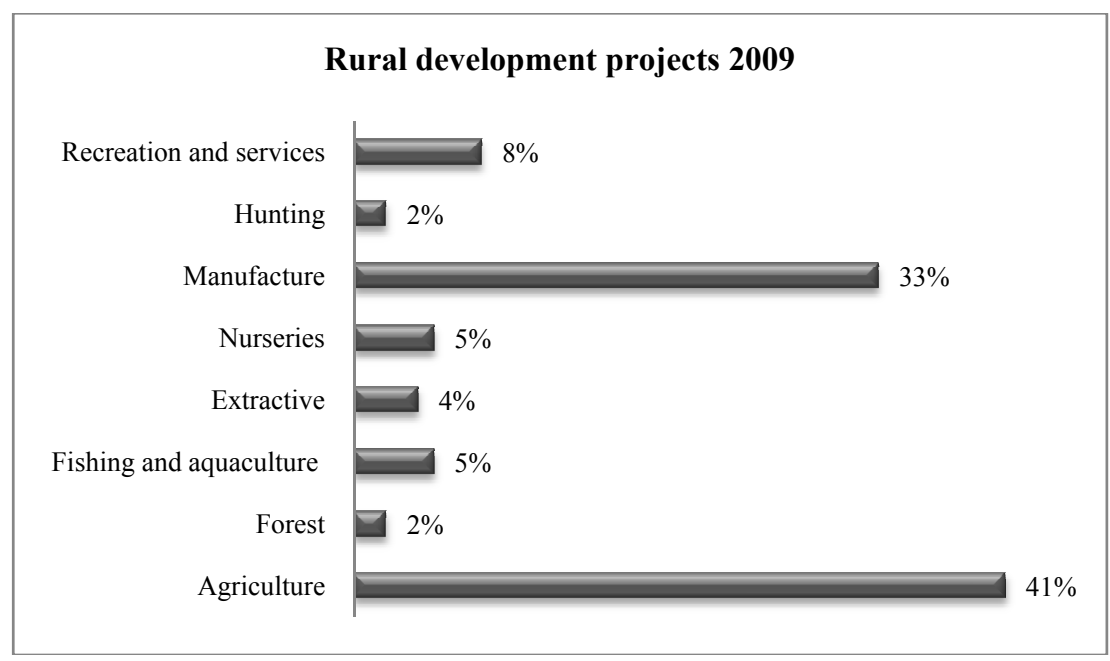

Source: Made by author, Colima RENDRUS information.

Figure 3: Classification of rural development projects; best practices in Comala, Colima.

As for the presented projects' analysis, throughout the 2006-2009 period a total of 55 companies participated, $61 \%$ to the primary and $33 \%$ to the secondary sector, and $8 \%$ in services, which still reflects a lesser impact towards secondary and service activities (Table 1).

Table 1: $\quad$ Participating enterprises.

\begin{tabular}{ccc}
\hline 2006-2009 & Companies & Percentage \\
\hline Agricultural & 23 & $41 \%$ \\
Forest & 1 & $2 \%$ \\
Fishing and Aquaculture & 3 & $5 \%$ \\
Extractive & 2 & $4 \%$ \\
Nurseries & 3 & $5 \%$ \\
Secondary/Manufacture & 18 & $33 \%$ \\
Hunting & 1 & $2 \%$ \\
Recreational/Services & 4 & $8 \%$ \\
Total & 55 & $100 \%$ \\
\hline
\end{tabular}

Source: Made by author, Colima RENDRUS information. 
One of the call requirements is the company established time; most of them are located in the primary sector in a range of 7 to 14 years, the ones in the secondary sector have an average of 12 years working, and the minorities are those relatively new located in services (Table 2).

Table 2: $\quad$ Age of the enterprises.

\begin{tabular}{ccc}
\hline Age of the companies & $\begin{array}{c}\text { Number of } \\
\text { enterprises }\end{array}$ & $\begin{array}{c}\text { Average number } \\
\text { of years }\end{array}$ \\
\hline Agricultural & 9 & 12.1 \\
Forest & 0 & - \\
Fishing and Aquaculture & 0 & - \\
Extractive & 1 & 7.0 \\
Nurseries & 2 & 8.5 \\
Manufacture & 11 & 8.3 \\
Hunting & 1 & 14.0 \\
Recreational/Services & 2 & 8.0 \\
\hline
\end{tabular}

Source: Made by author, Colima RENDRUS information.

In order to receive any economic support, the companies must be formally established. Most of them are of constituted by families, with a varied number of working partners. As shown in Table 3, the number of members varies from 6 to 14.

Table 3: $\quad$ Average of partners per enterprise.

\begin{tabular}{cccc}
\hline 2006-2009 & $\begin{array}{c}\text { Number of } \\
\text { Partners }\end{array}$ & $\begin{array}{c}\text { Number of } \\
\text { companies }\end{array}$ & $\begin{array}{c}\text { Average } \\
\text { number of } \\
\text { partners }\end{array}$ \\
\hline Agricultural & 109 & 11 & 9 \\
Forest & 28 & 1 & 28 \\
Fishing and Aquaculture & 6 & 1 & 6 \\
Extractive & 237 & 1 & 237 \\
Nurseries & 16 & 1 & 8 \\
Secondary/Manufacture & 169 & 12 & 14 \\
Hunting & $*$ & - & - \\
Recreational/Services & 19 & 2 & 9.5 \\
\hline
\end{tabular}

Source: Made by author, Colima RENDRUS/SRDNN information.

*Enterprises that did not provide partner information.

Of the six established criteria, from least to most impact in the companies, the following can be said: First, in the sustainability and environmental rubric for the evaluated period, most of the projects per year had fewer opinions over how they conducted the resources sustainable management application in primary, secondary and service activities. The projects that responded to this aspect were the ones involved with forests and hunting activities. Given that this aspect is relevant within the model, the different sectors must have guidance on the strategies they could include minimizing the environmental impact (Figure 4). 


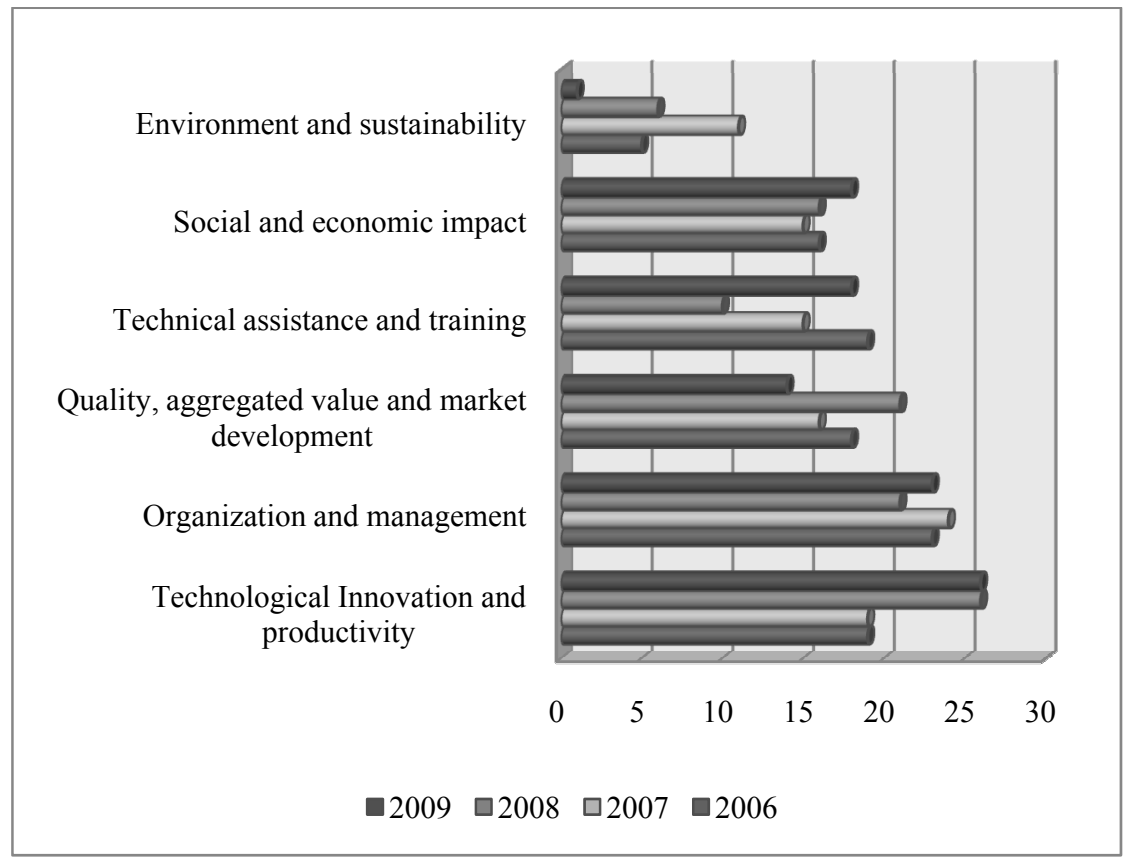

Source: Made by author, Colima RENDRUS information.

Figure 4: $\quad$ Self-assessment criteria 2006-2009.

Second, on economic and social impact, the opinions were constant each year by the companies, which pointed out some economic benefits they had, even though this were not significant, either by increasing the product's quality and production, or by venturing in other markets. Nonetheless, no reference was made on the improvements of the family living standards, on the collective or on their localities.

Third; in all cases, the companies have received support for technical training in both production processes and in projects management, the importance of this rubric varies from case to case, where some companies have been able to escalate some projects or diversify their activities.

Fourth; in terms of quality, added value and market development, the opinions consider having achieved higher quality products, and thus having higher income expectations, relevant in their companies, situation which was not direct in all cases, as some had high cost production and regulation problems or a lack of knowledge of the markets demanding that type of product. Although progress in this point has been slow, in some cases the products' diversification or the venture into secondary and service activities were facilitated.

Fifth, all companies considered crucial the organization and administration aspect in achieving goals, as it has allowed them the improvement of the conditions ranging from the society's formalization to the association with other companies, which demands review processes of production and organization 
forms, for which the key has been continuous training and update, given the dynamic market conditions and the management of technologies.

Sixth, the productive and technological innovation is considered as priority, since it is reported as a positive aspect for the support they receive for the development of the infrastructure, buildings and the companies' equipment, and the possibilities to increase the production and to improve the products' quality. This aspect has also represented a limitation in the companies' progress, especially in the starting phase.

From the previous, it can be said that for both the start and the operation of companies, the strengthening of the organization and administration, together with the demands and dynamics that the continuous productive and technological innovation requires to increase the competitiveness, must be constant. However, the training of producers and service providers on clean production and sustainable management of their resources, along with the orientation of partners and companies on evaluation forms through economic, environmental and social indicators are required.

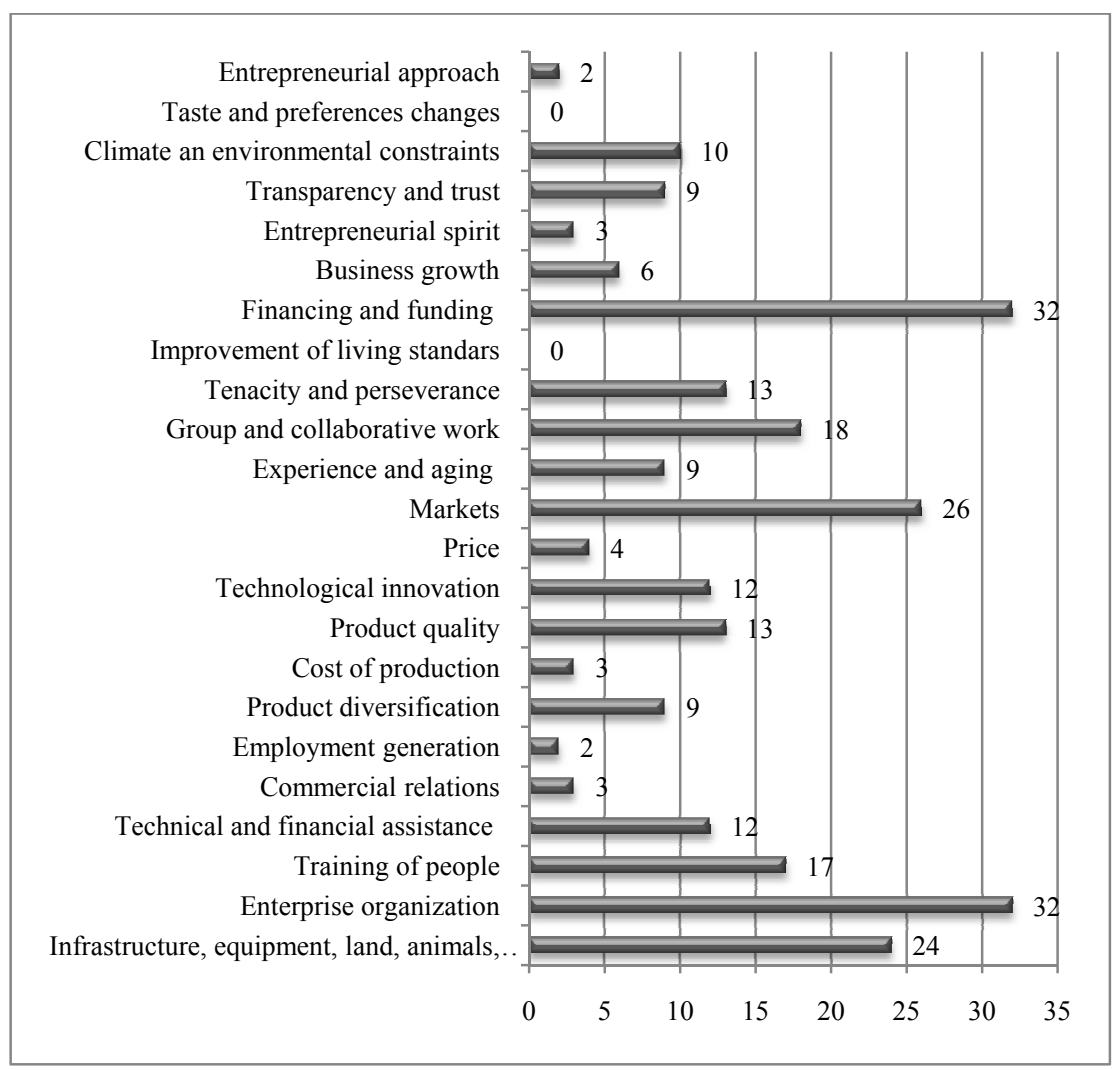

Source: Made by author, Colima RENDRUS information.

Figure 5: Successful factors in best practices 2006-2009. 
From the success and adverse factors analysis, the following can be said: there is no doubt in the role that government and private funding aspects have had at the companies' start, maintenance and growth, as well as with the role the organization, training, team and collaborative work they develop to be more efficient, plus the value assigned to the market infrastructure and knowledge for achieving goals. On the adverse factors side, it is interesting to note that they are practically the same as the previously analyzed, with the exception of the climatic changes that can significantly affect the production or the sudden rise or fall of the products in the market, affecting the company's possible success.

\section{Conclusions}

The SRD model instrumentation has been slow, talking about almost 10 years of work, which means a short time when referring to long-term planning and the management of sustainability. The efforts have focused primarily on the formation and organization of sustainable rural development councils (national, regional, state, district and municipal), as well as in its regulations and in the municipal development diagnostics that result in the rural municipal development plans and its particular needs. Another great effort consists in the execution of concurrent annual tasks that encourage the development based on the specific diagnostic of each municipality, district and region.

The sectorial management of primary activities is to be found operating the fastest, and to a lesser extent, the secondary derived from the field. The aspects that still remain disintegrated from the practice are the relation between rural and urban systems. This means that the sectorial mentality still underlies the institutions that have not fully achieved the coordination and concurrence of integrative plans with common goals, as set by the law in the coordination agreements of the three government levels.

This project has two paths: one towards the business and linkages promotion and the other towards the attention to poverty. In that sense, this work focuses only on a small part of the general project. The first case is based on the existence of an organization and of short and medium term planning exercises, but on the second case, a large population number is found, whose only horizon is the one set by its daily needs subsidized through poverty combat programs.

There is a nationwide effort to keep a record of best practices, but it would be more efficient if from this an indicator base that allows a qualitative and quantitative evaluation of the group of projects were created. However, it is worrying that the official sector, SAGARPA, only has one evaluation system on the application of economic resources and sectorial administrative efficiency, leaving aside the projects that over time have not even been able to self-assess in order to learn something about themselves, both positively or negatively.

Of all cases, two basic approach aspects stand out: the first refers to the poor training on environmental issues of the institutions, producers and the general public, as the experiences show that the sustainability still lies on paper and speech, and not in the practice, and that also, due to that lack of formation, information concerning the rational and sustainable use of resources gets lost, as 
it is not seen or detected by the stakeholders, delimiting the sustainability criteria just to efficiency processes and pollution. The other aspect is that this proposal pretends to influence in the welfare of the population, nonetheless, the people participating in the projects do not externalize the benefits regarding the individual and the collective, since only the economic benefits of the obtained resources are detected. Finally, a part intended for the evaluation of the administration in charge of operating the program, which is not included even qualitatively in the methodology, is included within the model.

\section{References}

[1] Herrera, T.F., Politicas públicas para el desarrollo rural: estudio de los programas de la "alianza para el campo" de México. Tesis Doctoral, Facultad de Ciencias, Instituto de Investigación en ciencias Agropecuarias y Rurales, UAM, México, 2008.

[2] Schejtman, A., Berdegué, J.A., Desarrollo territorial rural, RIMISP, Borrador de Trabajo, Santiago de Chile, pp.17-29, 2003. http://www.rimisp.org /documentos /desarrolloterritorial.pdf

[3] Sepulveda, S., Rodriguez, A., Echeverri, R., Portilla, M., El enfoque territorial del desarrollo rural, Instituto Interamericano de Cooperación para la agricultura, San José de Costa Rica, 2003.

[4] Boisier, S., Desarrollo territorial y descentralización: El desarrollo en el lugar y en las manos de la gente. EURE, vol.30, n.90, pp. 27-40, 2004. http://www.scielo.cl/scielo.php?script $=$ sci arttext\&pid $=$ S0250$71612004009000003 \& \operatorname{lng}=$ es\&nrm=iso

[5] Carton de Grammont, H. ¿Nueva ruralidad o nueva sociología rural?, Memorias VIII Congreso de la Asociación Latinoamericana de Sociología Rural, pp. 25, Porto de Galinhas, Pernambuco, Brasil, 2010. http://www.alasru.org/cdalasru2010/1\%20trabalhos\%20completos/mesas/H ubert $\% 20$ de $\% 20$ Grammont.pdf

[6] Miranda, C., Matos, A., Desarrollo rural sostenible enfoque territorial: la experiencia de IICA en Brasil, Instituto Interamericano de Cooperación para la Agricultura, Brasilia, pp. 17-21, Nov.2002.

[7] Uribe, N.B., Desarrollo rural integral: gestión territorial de México, Subdelegación de planeación del Estado de México, México, Online: http://www.monografias.com/trabajos37/desarrollo-rural-mexico/desarrollorural-mexico.shtml

[8] Diario Oficial de la Federación, Ley de Desarrollo Rural Sustentable, 7 diciembre de 2001.

[9] RENDRUS-SAGARPA,(s/f), Red Nacional de Desarrollo rural Sustentable, http://www.rendrus.org/ 